\title{
Electric Fields Produced in Cubic Crystals by Point Defects
}

\author{
A. D. Franklin* and D. J. Sparks ${ }^{1}$ \\ Theoretical Physics Division, U.K.A.E.A., Harwell, England
}

(October 8, 1966)

\begin{abstract}
Charged point defects in crystals polarize the surrounding ions. These induced dipoles contribute to the electric field in the crystal. In this paper, lattice sums for the calculation of this contribution are given for the $\mathrm{NaCl}, \mathrm{CsCl}, \mathrm{CaF}_{2}$, and $\mathrm{ZnS}$ structures. Various positions for the defect are chosen, and the field evaluated near lattice sites in the vicinity of the defect, with radial (with respect to the defect) displacements of \pm 20 percent of the cation-anion distance allowed away from each lattice site. The lattice sums are expressed in power series, including terms up to cubic in the displacements, and the coefficients tabulated.
\end{abstract}

Key Words: Electric fields, ionic crystals, lattice sums, point defects, polarization, $\mathrm{NaCl}, \mathrm{CsCl}$, $\mathrm{CaF}_{2}, \mathrm{ZnS}$.

\section{Electric Fields From Defects in Cubic Crystals}

Impurities and other point defects in ionic crystals polarize the ions around them. The electric field produced at a neighboring ion is the sum of the field due to the charge on the defect plus the fields due to dipoles (electronic and displacement) induced upon all the other surrounding ions. In the dielectric continuum model of Mott and Littleton, ${ }^{2}$ the induced dipole on the $i$ th ion is

$$
\mathbf{m}_{i}=(\Delta q) \frac{r_{0}^{3} M_{ \pm} \mathbf{r}_{i}}{r_{i}^{3}}
$$

where $\mathbf{r}_{i}$ is the vector from the defect to $i$ th ion, $\Delta q$ is the difference between the charge on the defect and that normally associated with the site occupied by the defect, $r_{0}^{3}$ is the volume of crystal containing one molecule $M_{a} X_{b}$, and

$$
M_{ \pm}=\frac{\alpha_{ \pm}}{a \alpha_{+}+b \alpha_{-}} \frac{K-1}{4 \pi K}
$$

with $\alpha_{ \pm}$the polarizability of the $\left\{\begin{array}{l}\text { cation } \\ \text { anion }\end{array}\right\}$ and $K$ the static dielectric constant of the crystal.

If the vector from the $i$ th to the $j$ th ion be designated $\mathbf{r}_{i j}$, then the field at the $j$ th ion due to the induced dipoles on all the other ions is

$$
\mathbf{F}_{j}=\sum_{i \neq j}\left\{\frac{3\left(\mathbf{m}_{i} \cdot \mathbf{r}_{i j}\right) \mathbf{r}_{i j}}{r_{i j}^{5}}-\frac{\mathbf{m}_{i}}{r_{i j}^{3}}\right\}
$$

*Work done while on temporary attachment from the National Bureau of Standards, W ashington, D.C.

${ }^{1}$ Present address, Trinity College, Cambridge, England.

${ }^{2}$ N. F. Mott and M. J. Littleton, Trans. Far. Soc. 34, 485 (1938).
If the defect is taken as the origin, and with $\mathbf{r}_{j} /\left|r_{j}\right|=\boldsymbol{\eta}_{j}$ and the vectors expressed as

$$
\mathbf{r}=a(h \mathbf{x}+k \mathbf{y}+l \mathbf{z})
$$

where $\mathbf{x}, \mathbf{y}$, and $\mathbf{z}$ are the coordinate axes, eq (2) can be written as

$$
\mathbf{F}_{j} \cdot \boldsymbol{\eta}_{j}=\frac{\Delta q r_{0}^{3}}{a^{5}}\left\{M_{+} S_{j C}+M_{-} S_{j A}\right\}
$$

The quantities $S_{j C}$ and $S_{j A}$ are lattice sums over the cation and anion sites respectively, and have the form

$$
S_{j}=\sum_{i} \frac{2 P_{j i} P_{j j}-3 P_{i i} P_{j j}-P_{j i}^{2}+2 P_{i i} P_{j i}}{P_{j j}^{1 / 2} P_{i i}^{3 / 2}\left[P_{j j}-2 P_{j i}+P_{i i}\right]^{5 / 2}}
$$

with

$$
\begin{aligned}
& P_{j j}=h_{j}^{2}+k_{j}^{2}+1_{j}^{2} \\
& P_{j i}=h_{j} h_{i}+k_{j} k_{i}+1_{j} 1_{i} \\
& P_{i i}=h_{i}^{2}+k_{i}^{2}+1_{i}^{2} .
\end{aligned}
$$

The sum does not include the origin nor the evaluation point $j$, but does include in principle all other lattice sites. The evaluation point $j$ need not be at a lattice site; by taking nonintegral values of $h_{j}, k_{j}$, and $l_{j}$, the sums appropriate to other positions may be found.

The lattice sums have been evaluated by computer for several cubic structures, with the defect occupying various lattice sites and with the evaluation of the field also at or near several different lattice sites. The evaluation point was allowed to move away from the lattice site a distance and direction specified in each case by a single parameter $X$. This parameter is so 
defined that if $\mathbf{r}$ is the radius vector from the defect at the origin to the lattice site, $(1+A X) \mathbf{r}$ is the radius vector of the evaluation point, with $A$ chosen to make the displacement of the evaluation point from the lattice site approximately $\mathrm{a} / 10$ when $X=1$. The sums were evaluated near a given lattice site with $X$ equal to $-2,-1,0,1$, and 2 . From these five values for $S_{j}$, the coefficients in the interpolation formula

$$
S_{j}=S_{j}^{\circ}+X S_{j}^{\prime}+X^{2} S_{j}^{\prime \prime}+X^{3} S_{j}^{\prime \prime \prime}
$$

were found by making the series agree exactly with the calculated sums at $X=-1,0$, and 1, and fit approximately, by least squares, at $X=-2$ and 2 . The values of $S_{j}$ at $|X|=2$ are accurate to about 1 percent. Convergence in the calculated fields was assumed to have been achieved when the total contribution from a given set of ions, with the same numerical values of $h, k, l$, was less than the total from all ions included divided by $10^{5}$.
TABLE la. Sets of coefficients for use in eq (5)

\begin{tabular}{l|r|r|r|r}
\hline \hline Set & $S^{\circ}$ & \multicolumn{1}{c|}{$S^{\prime}$} & \multicolumn{1}{c}{$S^{\prime \prime}$} & \multicolumn{1}{c}{$S^{\prime \prime}$} \\
\hline & & & & \\
$\mathrm{A}$ & -5.8952 & 0.6078 & 0.2513 & -0.01102 \\
$\mathrm{~B}$ & -1.2153 & -.5796 & -.0599 & .00930 \\
$\mathrm{C}$ & -2.3713 & .2846 & -.0107 & -.00091 \\
$\mathrm{D}$ & -0.3880 & -.0538 & .0012 & .00011 \\
$\mathrm{E}$ & -1.9650 & -.1714 & .0593 & .00755 \\
$\mathrm{~F}$ & -2.2874 & .5183 & .0530 & .00171 \\
$\mathrm{G}$ & -1.3537 & .1015 & .0020 & -.00066 \\
$\mathrm{H}$ & -0.7302 & -.0820 & .0050 & -.00019 \\
$\mathrm{I}$ & -.2467 & -.0305 & .00006 & -.01745 \\
$\mathrm{~J}$ & -8.2036 & 1.2307 & -.0110 & -.00298 \\
$\mathrm{~K}$ & -0.4697 & -0.1865 & -.0336 & -.00173 \\
$\mathrm{~L}$ & -7.1106 & .0282 & .1914 & -.03626 \\
$\mathrm{M}$ & -11.5685 & 2.3025 & -.0697 & .00829 \\
$\mathrm{~N}$ & -0.0614 & -0.3048 & -.0935 & .00766 \\
$\mathrm{O}$ & -2.3529 & -.2252 & .0605 & .00189 \\
$\mathrm{P}$ & -2.0496 & .8115 & -.1610 & .00003 \\
$\mathrm{Q}$ & -2.6663 & -.1731 & .0557 & .00042 \\
$\mathrm{R}$ & -0.9769 & -.1125 & .0050 & .00072 \\
$\mathrm{~S}$ & -2.3570 & -.3536 & -.0255 & -.01787 \\
$\mathrm{~T}$ & -0.5922 & & -.0068 & -.00370 \\
$\mathrm{U}$ & -5.8465 & .8771 & .0145 & \\
$\mathrm{~V}$ & 0.1222 & -.1132 & -.0404 & \\
& & & & \\
\hline & & & & \\
\hline
\end{tabular}

TABLE 1b. Electric fields in cubic crystals from dipoles induced by point defects, using eqs 4 and 5 and the coefficients in table la

\begin{tabular}{|c|c|c|c|c|c|c|c|c|c|}
\hline \multirow{2}{*}{ Structure } & \multirow{2}{*}{$\begin{array}{l}\text { Distance denoted' } \\
\text { by "a" (eq } 3 \text { ) }\end{array}$} & \multirow{2}{*}{ Defect site } & \multirow{2}{*}{ Evaluation point } & \multicolumn{3}{|c|}{ Anions } & \multicolumn{3}{|c|}{ Cations } \\
\hline & & & & Inside & $\begin{array}{l}\text { Same } \\
\text { Shell }\end{array}$ & Outside & Inside & $\begin{array}{l}\text { Same } \\
\text { Shell }\end{array}$ & Outside \\
\hline $\mathrm{NaCl}$ & Cation-anion & Cation [anion at $(0,0,1)$ ] & $\begin{array}{l}(1+0.1 X)(1 / 2,1 / 2,1 / 2) \\
(1+0.08 X)(0,0,1) \\
(1+0.05 X)(0,1,1)\end{array}$ & $\mathrm{F}$ & C & $\begin{array}{l}\text { A } \\
\text { D } \\
\text { H }\end{array}$ & & G & $\begin{array}{l}\text { B } \\
\text { E } \\
\text { I }\end{array}$ \\
\hline $\mathrm{CsCl}$ & Cation-cation & Cation [anion at $(1 / 2,1 / 2,1 / 2)]$ & $\begin{array}{l}(1+0.1 \mathrm{X})(1 / 2,1 / 2,1 / 2) \\
(1+0.08 \mathrm{X})(0,0,1) \\
(1+0.05 \mathrm{X})(0,1,1)\end{array}$ & $\stackrel{\mathrm{M}}{\mathrm{P}}$ & $\mathbf{J}$ & $\begin{array}{l}\mathrm{K} \\
\mathrm{N} \\
\mathrm{Q}\end{array}$ & $F$ & $\begin{array}{l}\mathrm{C} \\
\mathrm{G}\end{array}$ & $\begin{array}{l}\mathrm{L} \\
\mathrm{O} \\
\mathrm{R}\end{array}$ \\
\hline \multirow[t]{3}{*}{$\mathrm{CaF}_{2}$} & Anion-anion & Cation [anion at $(1 / 2,1 / 2,1 / 2)]$ & $\begin{array}{l}(1+0.1 X)(1 / 2,1 / 2,1 / 2) \\
(1+0.8 X)(0,0,1) \\
(1+0.05 X)(0,1,1)\end{array}$ & $\begin{array}{l}\mathrm{M} \\
\mathrm{P}\end{array}$ & $J$ & $\begin{array}{l}\mathrm{K} \\
\mathrm{N} \\
\mathrm{Q}\end{array}$ & & G & $\begin{array}{l}\mathrm{B} \\
\mathrm{E} \\
\mathrm{I}\end{array}$ \\
\hline & & $\begin{array}{l}\text { Empty cube center } \\
\quad[\text { Anion at }(1 / 2,1 / 2,1 / 2)]\end{array}$ & $\begin{array}{l}(1+0.1 X)(1 / 2,1 / 2,1 / 2) \\
(1+0.08 X)(0,0,1) \\
(1+0.05 X)(0,1,1)\end{array}$ & $\stackrel{\mathrm{M}}{\mathrm{P}}$ & $\mathrm{J}$ & $\begin{array}{l}\mathrm{K} \\
\mathrm{N} \\
\mathrm{Q}\end{array}$ & F & C & $\begin{array}{l}\text { A } \\
\text { D } \\
\text { H }\end{array}$ \\
\hline & & Anion [cation at $(1 / 2,1 / 2,1 / 2)]$ & $\begin{array}{l}(1+0.1 \mathrm{X})(1 / 2,1 / 2,1 / 2) \\
(1+0.08 \mathrm{X})(0,0,1) \\
(1+0.1 \mathrm{X})(1 / 2,1 / 2,-1 / 2)\end{array}$ & & C & $\begin{array}{l}\mathrm{L} \\
\mathrm{O} \\
\mathrm{L}\end{array}$ & $\mathrm{M} / 2$ & $\begin{array}{l}\mathrm{S} \\
\mathrm{U}\end{array}$ & $\begin{array}{l}\mathrm{T} \\
\mathrm{N} / 2 \\
\mathrm{~V}\end{array}$ \\
\hline \multirow[t]{2}{*}{ Zinc-blende } & (Cation-cation) $/ \sqrt{2}$ & Anion [cation at $(1 / 2,1 / 2,1 / 2)]$ & $\begin{array}{l}(1+0.1 X)(1 / 2,1 / 2,1 / 2) \\
(1+0.08 X)(0,0,1) \\
(1+0.1 X)(1 / 2,1 / 2,-1 / 2)\end{array}$ & & & $\begin{array}{l}\mathrm{B} \\
\mathrm{E} \\
\mathrm{B}\end{array}$ & $\mathrm{M} / 2$ & $\begin{array}{l}\mathrm{S} \\
\mathrm{U}\end{array}$ & 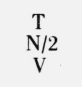 \\
\hline & & $\begin{array}{l}\text { Midpoint of unit cell edge } \\
{[\text { cation at }(1 / 2,1 / 2,1 / 2)]} \\
{[\text { anion at }(1,0,0)]}\end{array}$ & $\begin{array}{l}(1+0.1 X)(1 / 2,1 / 2,1 / 2) \\
(1+0.08 X)(0,0,1) \\
(1+0.1 X)(1 / 2,1 / 2,-1 / 2)\end{array}$ & & C & $\begin{array}{l}\text { A } \\
\text { D } \\
\text { A }\end{array}$ & $\mathrm{M} / 2$ & $\begin{array}{l}\mathrm{S} \\
\mathrm{U}\end{array}$ & $\underset{\mathrm{T}}{\mathrm{T}} \mathrm{V}$ \\
\hline
\end{tabular}

The results, in the form of the coefficients in the power series, are given in table 1. Each set of coefficients occurs several times, so for the sake of economy these sets are listed together in table la and given symbols. In table $1 \mathrm{~b}$, these symbols are used to indicate the set of coefficients appropriate to the situation described in the first four columns of the table.

With the defect at the origin, the ions in the crystal can be divided into three groups: those on the shell that includes the lattice site around which the evaluation is being performed ("same shell"), all those within this shell ("inside"), and all those outside of it ("outside"). In the last six columns, the contributions to $S_{j}$ from anions and cations in these three groups are listed separately. Values for $S^{\circ}$ symbolized by $D, E$, $T$, and $V$ have already been given by Mott and Littleton (see footnote 2).

(Paper 71Al-428) 